\title{
Konsensus Dokter Umum Mengenai Materi Inti Anatomi Sistem Reproduksi Wanita Untuk Mahasiswa Kedokteran
}

\author{
Intan Pratiwi ${ }^{1}$, Yunia Hastami ${ }^{2}$, Nanang Wiyono ${ }^{2}$, Siti Munawaroh ${ }^{2}$ \\ 1.Program Studi Kedokteran Fakultas Kedokteran Universitas Sebelas Maret \\ 2.Bagian Anatomi Fakultas Kedokteran Universitas Sebelas Maret
}

Korespondensi : intanpratiwi@ student.uns.ac.id

\begin{abstract}
ABSTRAK
Pendahuluan: Anatomi sistem reproduksi wanita merupakan salah satu ilmu dasar praktik klinis kedokteran yang diperlukan oleh dokter umum. Hingga saat ini belum ada standardisasi mengenai materi anatomi sistem reproduksi wanita. apa saja yang perlu diketahui oleh mahasiswa kedokteran. Sementara itu, kurikulum kedokteran telah mengalami banyak perubahan yang berdampak pada waktu pembelajaran yang berkurang sehingga berakibat pengurangan materi anatomi yang diberikan kepada mahasiswa. Hal ini menyebabkan perbedaan penekanan materi anatomi yang diberikan berbeda-beda pada masing-masing institusi kedokteran. Penelitian ini bertujuan untuk menyusun pokok materi anatomi sistem reproduksi wanita agar dapat mempermudah pembelajaran anatomi bagi mahasiswa kedokteran.

Metode: Penelitian ini merupakan penelitian kualitatif dengan metode delphi 2 putaran. Subyek penelitian adalah dokter umum yang berasal dari 9 institusi di Indonesia, dipilih melalui purposive sampling sebanyak 20 orang. Kuesioner awal delphi disusun berdasarkan tiga buku teks anatomi, satu terminologi anatomica, dan satu penelitian tentang materi inti anatomi. Delphi putaran I panel diminta untuk memilih materi yang penting dan dapat menambahkan materi jika belum ada. Delphi putaran II panel diminta memberi rangking 1-4 pada setiap materi. Peneliti menetapkan level konsensus sebesar $53 \%$.

Hasil: Hasil Delphi putaran I didapatkan 176 materi dari total 178 materi dan tidak didapatkan materi tambahan. Delphi putaran II didapatkan materi inti anatomi sebanyak $84(47.72 \%)$ dari 176 materi.
\end{abstract}

Kesimpulan: Konsensus dokter umum mengenai materi inti anatomi sistem reproduksi wanita sebanyak 84.

Kata Kunci: anatomi, materi inti, sistem reproduksi wanita, konsensus dokter umum, metode Delphi.

\begin{abstract}
Introduction: The anatomy of the female reproductive system is one of the basic sciences of medical clinical practice needed by general practitioners. Until now there has been no standardization regarding anatomical material of the female reproductive system that medical students need to know. Meanwhile, the medical curriculum has undergone many changes that have impacted on reduced learning time resulting in a reduction in anatomical material given to students. This causes the different emphasis on anatomical material given to be different for each medical institution. This study aims to compile the subject matter of the anatomy of the female reproductive system in order to facilitate anatomical learning for medical students.

Methods: This research is a qualitative research with Delphi method two rounds. The subjects were general practitioners from 9 institutions in Indonesia selected through purposive sampling as many as 20 people. The initial Delphi questionnaire was compiled
\end{abstract}


based on three anatomical textbooks, one anatomic terminology, and one study on the anatomical core material. Delphi round I panel is asked to choose material that are important and can add material if it doesn't already exist. Delphi round II panel was asked to rank 1-4 in each material. Researchers set a consensus level of 53\%.

Results: The results of Delphi round I obtained 176 materials from a total of 178 materials and no additional material was obtained. Delphi round II obtained $84(47.72 \%)$ core anatomical materials from 176 material.

Conclusion: General practitioners consensus of core materials of female reproductive system anatomy is 84 materials.

Keywords: anatomy, core syllabus, female reproductive system, general physician consensus, Delphi method.

\section{PENDAHULUAN}

Anatomi merupakan salah satu ilmu dasar praktik klinis kedokteran serta ilmu yang penting dalam kedokteran ${ }^{1,2}$. Anatomi memberikan dasar bagi mahasiswa kedokteran untuk mempelajari struktur tubuh sehingga mereka mampu memahami hubungan struktur, fungsi, maupun keabnormalan yang terjadi. Oleh karena itu, anatomi menjadi salah satu isi kurikulum kedokteran yang wajib dalam pendidikan kedokteran di Indonesia ${ }^{3}$.

Saat ini, kurikulum kedokteran telah mengalami banyak perubahan seperti diterapkannya kurikulum kedokteran berbasis kompetensi yang bertujuan agar lulusan pendidikan kedokteran mampu menerapkan ilmu yang dipelajari dengan relevansi klinisnya $^{2}$. Penerapan kurikulum berbasis kompetensi ini membebaskan tiap institusi pendidikan dokter dalam menetapkan materimateri apa saja yang akan diberikan kepada mahasiswa kedokteran. Tidak adanya materi inti anatomi yang wajib diberikan kepada mahasiswa kedokteran menyebabkan lulusan pendidikan dokter mempunyai kemampuan anatomi yang berbeda-beda. Bahkan terdapat laporan bahwa ada lulusan dokter muda melakukan malpraktik dikarenakan kurangnya pengetahuan anatomi ${ }^{4}$.

Dampak lain perubahan pendidikan kedokteran adalah pengurangan waktu pembelajaran anatomi di berbagai institusi kedokteran. Akibatnya banyak materi yang harus disesuaikan dikarenakan hal tersebut ${ }^{5}$.
Selain itu, seiring dengan kemajuan teknologi bermunculan banyak cabang ilmu baru seperti biologi molekuler dan ilmu mikros lainnya yang menambah banyak beban mahasiswa kedokteran. Bertambah banyaknya ilmu yang harus dikuasai namun tidak diimbangi dengan penambahan alokasi waktu pembelajaran inilah yang menjadi salah satu sebab banyak mahasiswa yang merasa kurang pengetahuan mengenai anatomi ${ }^{6}$.

Beberapa penelitian telah dilakukan untuk membuat materi inti anatomi diantaranya adalah pengembangan materi inti anatomi kepala leher untuk mahasiswa kedokteran ${ }^{2}$, penyusunan core syllabus neuroanatomi untuk mahasiswa kedokteran ${ }^{7}$, identifikasi materi anatomi tulang yang sesuai dengan kasus klinis untuk mahasiswa kedokteran $^{1}$ dan konsensus dokter umum mengenai materi inti anatomi untuk mahasiswa program studi kedokteran ${ }^{8}$.

Sejauh ini berdasarkan penelusuran literatur, belum ada penelitian yang meneliti secara khusus mengenai materi inti anatomi untuk sistem reproduksi wanita. Penelitian ini akan difokuskan untuk mengetahui materi inti pada sistem reproduksi wanita yang dapat digunakan sebagai acuan pembelajaran anatomi bagi mahasiswa kedokteran.

\section{METODE}

Penelitian ini merupakan penelitian kualitatif dengan metode delphi 2 putaran. Lokasi penelitian di Indonesia. Populasi penelitian adalah dokter umum di Indonesia. 
Subjek penelitian dipilih menggunakan teknik purposive sampling sebanyak 20 orang dengan kriteria inklusi yaitu minimal praktik selama 3 tahun dan maksimal lulus dari sekolah kedokteran 10 tahun dari penelitian ini dilaksanakan.

Instrumen penelitian berupa kuesioner. Kuesioner berisi daftar materi anatomi sistem reproduksi wanita yang dibuat oleh peneliti dengan menggunakan beberapa literatur yaitu 3 buku teks, 1 terminologi anatomi dan 1 penelitian tentang materi inti anatomi.

Penelitian dilakukan dalam 2 putaran, pada putaran I panel memilih penting atau tidak penting pada materi serta dapat menambahkan materi apabila belum ada. Materi yang dipilih minimal oleh $50 \%$ panel akan diolah menjadi kuesioner delphi II. Pada delphi putaran II, panel diminta memberi rangking 1-4 pada setiap materi. Materi anatomi sistem reproduksi wanita dianggap penting apabila didapatkan minimal 53\% panel delphi memilih angka 3 (penting) dan 4 (sangat penting).

\section{HASIL}

\section{Karakteristik Subjek Penelitian}

Pada delphi putaran I, peneliti menyebar sebanyak 27 kuesioner kepada panel delphi dan kembali sejumlah 21 kuesioner (81\%). Kemudian pada delphi putaran II, peneliti menyebar kepada 20 panel delphi dan kuesioner yang kembali kepada peneliti sejumlah 17 kuesioner (85\%).

Tabel 1. Karakteristik Subjek

\begin{tabular}{lrr}
\hline \multicolumn{1}{c}{ Karakteristik } & $\begin{array}{c}\text { Jumlah } \\
(\mathrm{N})\end{array}$ & $\begin{array}{c}\text { Persentase } \\
(\%)\end{array}$ \\
\hline Jenis kelamin & & \\
Laki-laki & 4 & 23,5 \\
Perempuan & 13 & 76,5 \\
Usia (tahun) & & \\
25-29 & 2 & 11,8 \\
$30-34$ & 12 & 70,6 \\
\hline
\end{tabular}

\begin{tabular}{lll}
\hline $35-40$ & 3 & 27,6
\end{tabular}

\section{Pendidikan}

terakhir

S1

$12 \quad 70,6$

S2

$5 \quad 29,4$

Tahun kelulusan

$2008-2011$

$13 \quad 76,5$

$2012-2014$

4

23,5

\section{Lama berpraktek}

\section{sebagai dokter}

umum (tahun)

$\begin{array}{lll}3-5 & 7 & 41,2 \\ 6-8 & 4 & 23,5 \\ 9-11 & 6 & 35,3\end{array}$

Alamat

Samarinda $\quad 1 \quad 5,9$

Depok $3 \quad 17,6$

Bekasi $\quad 1 \quad 5,9$

$\begin{array}{llr}\text { DIY } & 1 & 5,9\end{array}$

Klaten $\quad 2 \quad 11,8$

$\begin{array}{lll}\text { Surakarta } & 3 & 17,6\end{array}$

Mojokerto $\quad 1 \quad 5,9$

$\begin{array}{lll}\text { Sragen } & 2 & 11,8\end{array}$

$\begin{array}{lll}\text { Sukoharjo } & 2 & 11,8\end{array}$

\begin{tabular}{lll} 
Temanggung & 1 & 5,9 \\
\hline
\end{tabular}

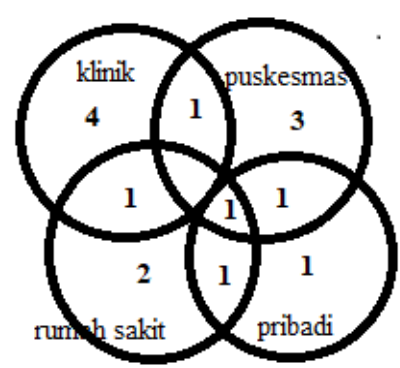

Gambar 1. Karakteristik Subjek tentang asal institusi

\section{Delphi putaran I}

Kuesioner delphi putaran I terdiri dari 8 topik sistem reproduksi wanita yang berjumlah 178 materi. Hasil yang didapatkan pada kuesioner putaran I yaitu materi yang dipilih penting oleh minimal 50\% panel 
berjumlah 176 dari total 178 materi. Tidak terdapat materi yang ditambahkan oleh panel.

\section{Delphi putaran II}

Jumlah materi yang masuk putaran II adalah 176 materi, kemudian hasil dari putaran II dengan menetapkan level konsensus sebesar $53 \%$ didapatkan materi inti sebanyak 84 atau sebanyak $47,72 \%$.

Tabel 2. Rangkuman hasil Delphi

\begin{tabular}{llrr}
\hline No & Topik & $\begin{array}{l}\text { Jumlah } \\
\text { materi } \\
\text { delphi I }\end{array}$ & $\begin{array}{l}\text { Jumlah } \\
\text { materi } \\
\text { inti }\end{array}$ \\
\hline 1 & Ovarium & 10 & 3 \\
2 & Tuba Fallopii & 11 & 9 \\
3 & Uterus & 28 & 15 \\
4 & Vagina & 7 & 7 \\
5 & Pelvis dan & 54 & 27 \\
& Perineum & & \\
6 & Genitalia & 25 & 12 \\
& Eksterna & & \\
7 & Neurovaskular & 28 & 1 \\
& isasi Organa & & \\
& Genitalia & & \\
& Feminina & & \\
8 & Mammae & 13 & 10 \\
& Total & 176 & 84 \\
\hline
\end{tabular}

\section{PEMBAHASAN}

\section{Proses Penelitian}

Penelitian ini bertujuan untuk mendapatkan konsensus materi inti anatomi sistem reproduksi wanita menggunakan metode Delphi dua putaran. Penelitian ini mengadopsi penelitian-penelitian yang telah dilakukan sebelumnya yaitu penelitian core syllabus anatomi untuk semua regio tubuh ${ }^{7}$ serta penelitian Konsensus Pakar Anatomi Indonesia mengenai Materi Inti Anatomi untuk Mahasiswa Pendidikan Dokter ${ }^{8}$.

Kuesioner delphi putaran I disusun berdasarkan buku teks agar semua strukur dapat masuk dalam kuesioner. Hal ini serupa dengan beberapa penelitian sebelumnya ${ }^{9,10}$. Kemudian, kuesioner tersebut dikonsulkan terlebih dahulu kepada ahli dalam bidang reproduksi. Berbeda halnya dengan penelitian yang dilakukan oleh Smith et al. dan Finn et al., telah ada silabus inti anatomi terlebih dahulu sehingga kuesioner Delphi putaran I berasal dari silabus yang sudah $\mathrm{ada}^{7,11}$. Kuesioner delphi putaran II merupakan hasil olahan delphi putaran I dengan menambahkan skala Likert.

Panel delphi merupakan dokter umum dengan alasan agar panel lebih memahami materi yang penting dipelajari oleh mahasiswa kedokteran. Ditetapkannya kriteria inklusi telah berpraktik minimal praktek 3 tahun dengan tujuan agar pengalaman panel dalam menghadapi kasus-kasus telah cukup untuk memahami materi anatomi apa sajakah yang ada di lapangan. Selain itu kriteria inklusi lainnya adalah maksimal lulus 10 tahun terhitung dari penelitian ini dilaksanakan. Hal ini bertujuan agar masih relevan dan tidak banyak perbedaan dalam pembelajaran kedokteran.

Terdapat beberapa perbedaan karakteristik panel dalam penelitian ini, yaitu mulai dari jenis kelamin, usia, pendidikan terakhir, tahun kelulusan, lama berpraktik, asal universitas, serta alamat. Tetapi hal itu tidak menunjukkan perbedaan yang berarti. Misalnya, panel berasal dari latar belakang pendidikan yang berbeda, yaitu S1 maupun S2 serta lulus dari 9 fakultas kedokteran yang berbeda-beda pula. Perbedaan ini tidak memberikan hasil jawaban yang berbeda. Poin 4 diberikan oleh semua panel pada materi posisi uterus. Selain itu, panel Delphi berasal dari daerah yang bervariasi. Baik panel dari Samarinda maupun Mojokerto memberikan poin penting pada materi endometrium. Karakteristik subjek penelitian ini tidak menjadi masalah dikarenakan peneliti menjelaskan mengenai cara pengisian kuesioner dengan seksama dan mengingatkan penel untuk selalu mengacu pada Standar Kompetensi Dokter Indonesia 2012.

Setiap panel delphi mempunyai pendapat yang berbeda-beda. Ada panel yang 
menganggap penting dan ada panel yang menganggap tidak penting. Oleh karena itu perlu ditetapkan konsensus minimal yaitu $53 \%$ untuk menentukan topik yang penting. Karena tidak ada aturan khusus tentang penentuan level konsensus maka penetapan konsensus ini didasarkan pada penelitianpenelitian sebelumnya dan pertimbangan dari ahli di bidang anatomi sistem reproduksi wanita $^{12}$.

\section{Pokok Materi yang Dihasilkan}

Materi inti yang didapat meliputi topografi, fungsi dari struktur-struktur serta struktur penting tiap organ. Bahkan materi seperti fungsi ovarium, posisi uterus, endometrium, fungsi vagina, dan fungsi mammae, seluruh panel Delphi sepakat untuk memilih penting semua/mendapatkan level konsensus $100 \%$. Kebanyakan panel yang memilih penting dikarenakan menurut mereka materi-materi tersebut sering ditemukan dan digunakan dalam praktik sehari-hari.

Terdapat 93 materi yang tidak dimasukkan ke dalam materi inti. Materi yang banyak dianggap tidak penting yaitu neurovaskularisasi organ genitalia feminina, ligamentum, musculus, serta struktur-struktur kecil. Alasan panel tidak memilih penting karena kurang memberikan makna klinis yang berarti dan jarang ditemui dalam praktik klinis. Akan tetapi sebenarnya banyak struktur yang menurut standar kompetensi dokter umum harus dimengerti seperti M. levator ani, corpus perineale, $\mathrm{N}$. pudendus, dan lain-lain untuk dapat melakukan ketrampilan klinis dengan aman dan efektif ${ }^{3}$.

Pada topik ovarium sebagian besar panel berpendapat memahami morfologi ovarium akan memudahkan pada saat melakukan pemeriksaan. Misalnya, pada kasus kista ovarium dengan bekal morfologi ovarium normal akan tau jika ada massa/jaringan yang abnormal.

Topik tuba fallopii didapatkan 9 materi inti dari 11 materi. Fungsi serta bagianbagian tuba fallopi dianggap penting karena berkaitan dengan beberapa penyakit pada wanita misalnya kehamilan ektopik(KET). Dijelaskan bahwa mekanisme kehamilan ektopik ada yang disebabkan oleh kelainan anatomi(obstruksi) tuba fallopii. Sehingga untuk dapat melakukan pemeriksaan, mendiagnosis, dan melakukan tindakan harus mempunyai pengetahui dasar anatomi tuba fallopi ${ }^{13}$.

Materi inti topik uterus yaitu 15 dari 28 materi. Materi yang terpilih meliputi fungsi, topografi, posisi, morfologi, otot dinding rahim. Beberapa panel memilih materi tersebut penting dikarenakan sering menemukan kasus di praktik mereka, seperti kelainan pada uterus, cervix uteri, endometrium. Cervix uteri penting dalam screening awal adanya keganasan serviks maupun infeksi, pada myometrium sering dijumpai mioma uteri, endometrium berhubungan dengan penegakan diagnosis menorraghia maupun metroraghia. Serangkaian proses pemeriksaan kehamilan dan kelahiran juga banyak menggunakan struktur pada topik ini, seperti pengukuran fundus uteri untuk mengetahui umur kehamilan atau ostium uteri eksternum untuk mengetahui bukaan persalinan ${ }^{3}$.

Topik vagina merupakan topik yang keseluruhan materinya masuk dalam materi inti. Dimungkinkan hal ini karena semua panel sepakat bahwa materi-materi pada topik ini penting dan menunjang dalam praktik klinik, yaitu diantaranya mengetahui dengan benar fungsi dan struktur vagina agar tidak salah ketika melakukan tindakan.

Pada topik pelvis dan perineum, materi yang masuk dalam materi inti sebanyak 27. Tulang penyusun pelvis dianggap penting sesuai dengan penelitian oleh Smith et al., ${ }^{7}$. Struktur di topik ini banyak mendukung dalam perhitungan ukuran-ukuran seperti simfisis ossis pubis, promontorium, SIAS, lineae arcuate, simfisis osis pubis.

Genitalia eksterna terdiri dari 12 materi inti. Panel dalam kolom korelasi klinis 
menyebutkan pentingnya strukur seperti himen dikarenakan sering diidentifikasi dalam kasus, kelenjar bartholini karena sering terjadi peyakit kista dan infeksi. Dengan mengetaui struktur-struktur tersebut diharapakan seorang dokter tidak salah dalam penatalaksanaan apabila terdapat kelainan disana.

Neurovaskularisasi organa genitalia feminina mendapatkan materi inti paling sedikit, hanya 1 dari 28 materi yang masuk materi inti yaitu a. ovarica. Hasil ini berbeda dengan penelitian yang dilakukan Munawaroh et al. dan Smith et al. yang mendapatkan bahwa neurovaskularisasi organ sistem reproduksi penting untuk dipelajari ${ }^{7,8}$. Para panel pada penelitian ini berpendapat bahwa persarafan dan vaskularisasi organ-organ tersebut kurang penting. Padahal dalam SKDI 2012 menyebutkan kompetensi dokter umum antara lain dapat melakukan anastesi lokal perineum dan melakukan episiotomi dalam melakukan proses melahirkan normal. Jika tidak mengetahui nervus yang harus diblokade dan arteri atau vena apa saja yang ada di wilayah itu, seorang dokter tidak dapat melakukan hal tersebut atau bahkan dapat membahayakan dalam melakukan prosedur tersebut.

Topik mammae didapat 10 dari 13 materi. Morfologi dan strukur mammae penting untuk melakukan pemeriksaan dan penegakan diagnosis kasus-kasus berlevel kompetensi 4A seperti mastitis, cracked nipple, inverted nipple.

Hambatan penelitian ini adalah beberapa panel sudah lupa materi anatomi sistem reproduksi wanita, terlebih strukurstruktur yang kecil. Panel harus membuka lagi buku teks untuk mengingat kembali struktur tersebut. Selain itu, hambatan lainnya adalah waktu para panel untuk mengisi kuesionernya dikarenakan kesibukan panel. Akan tetapi hal ini dapat ditanggulangi dengan mengingatkan panel secara berkala dan memberikan tenggang waktu kepada panel. sebagaimana yang diperlukan oleh tiap panel. Pada Delphi putaran II terdapat 3 panel yang tidak mengembalikan kuesioner. Hal ini disebabkan karena satu panel mengundurkan diri karena tidak dapat menyelesaikan pengisian kuesioner, satu panel tidak dapat mengisi sampai batas waktu yang diberikan, dan satu panel tidak dapat dihubungi kembali.

Dengan adanya hasil penelitian ini diharapkan materi anatomi lebih mudah dipelajari, sesuai kompetensi.

\section{KESIMPULAN}

Hasil konsensus dokter umum menyatakan bahwa materi inti anatomi sistem reproduksi wanita yaitu sejumlah 84 materi $(47,72 \%)$ dari 176 materi. Didapatkan pada topik ovarium sebanyak 3 materi, tuba fallopii sebanyak 9 materi, uterus sebanyak 15 materi, vagina sebanyak 7 materi, pelvis dan perineum sebanyak 27 materi, genitalia eksterna sebanyak 12 materi, neurovaskularisasi organa genitalia feminina sebanyak 1 materi, mammae sebanyak 10 materi.

\section{UCAPAN TERIMA KASIH}

Penulis mengucapkan terima kasih kepada semua pihak yang telah membantu terlaksananya penelitian ini khususnya dokter umum di Indonesia yang telah bersedia menjadi responden dalam penelitian.

\section{DAFTAR PUSTAKA}

1. Swamy M, Venkatachalam S, Mclachlan J. A Delphi consensus study to identify current clinically most valuable orthopaedic anatomy components for teaching medical students. 2014;14(1):15.

2. Tubbs RS, Sorenson EP, Sharma A, Benninger B, Norton N, Loukas M, et al. The development of a core syllabus for the teaching of head and neck anatomy to medical students. Clin Anat. 2014;27(3):321-30.

3. Konsil Kedokteran Indonesia. Standar 
Kompetensi Dokter. 2006. 1-90 p.

4. McHanwell S, Davies DC, Morris J, Parkin I, Whiten S, Atkinson M, et al. A core syllabus in anatomy for medical students - Adding common sense to need to know. Eur J Anat. 2007;11(SUPPL. 1):3-18.

5. Drake RL, Mcbride JM, Lachman N, Pawlina W. Medical Education in the Anatomical Sciences: The Winds of Change Continue to Blow. 2009;259(December):253-9.

6. Smith, Claire France and Mathias HS. What impact does anatomy education have on clinical practice? Clin Anat. 2011;24:113-9.

7. Smith CF, Finn GM, Stewart J, Mchanwell S. Anatomical Society core regional anatomy syllabus for undergraduate medicine: The Delphi process. J Anat. 2016;228(1):2-14.

8. Munawaroh S, Rahayu GR, Suryadi E, Mada UG. Identification Of Anatomy Contents For Medical. 2017;6(2):98-107.

9. Kilroy D, Driscoll P. Determination of required anatomical knowledge for clinical practice in emergency medicine: national curriculum planning using a modified Delphi technique. Emerg Med J [Internet]. 2006;23(9):693-6.

10. Moxham BJ, Plaisant $\mathrm{O}$, Smith $\mathrm{CF}$, Pawlina W, Mchanwell S. An Approach Toward the Development of Core Syllabuses for the Anatomical Sciences. 2014;1(August):302-11.

11. Finn GM, Hitch G, Apampa B, Hennessy CM, Smith CF, Stewart J, et al. The Anatomical Society core anatomy syllabus for pharmacists: outcomes to create a foundation for practice. J Anat. 2018;232(5):729-38.

12. Hsu C-C, Sandford BA. The Delphi technique. Dublin Natl Child Off. 2005;7(2):120-5.

13. Taran FA, Kagan KO, Hübner $\mathrm{M}$, Hoopmann M WD. The diagnosis and treatment of ectopic pregnancy. Brucker S Dtsch Arztebl Int. 2015;112:693-704. 